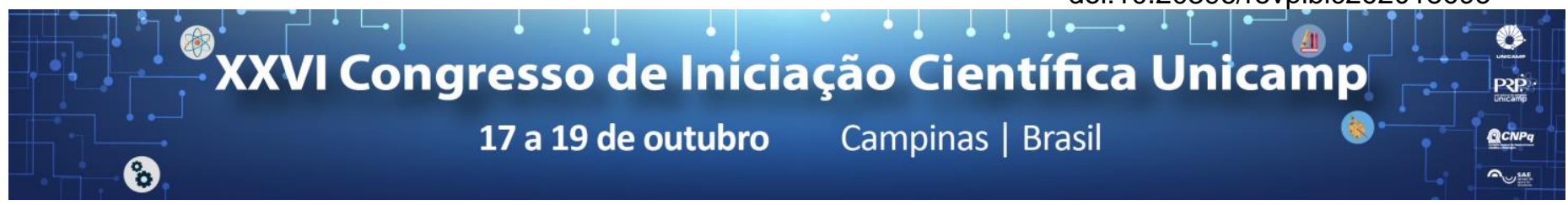

\title{
O cuidado farmacêutico ao paciente na Saúde da Família
}

\section{Jose V. Tolloto*, Rubens Bedrikow.}

\section{Resumo}

A pesquisa se propõs a estudar o cuidado farmacêutico ao paciente na Estratégia de Saúde da Família, isto é, a prática clínica do profissional farmacêutico. Conheceu-se como esses profissionais têm experimentado essa prática, pouco frequente até recentemente, dentro da concepção de que a assistência farmacêutica não mais limita seu foco no medicamento, passando a enfatizar o cuidado com as pessoas. Tratou-se de uma pesquisa qualitativa que se valeu de entrevistas semi-estruturadas com farmacêuticos que atuam em unidades de saúde da família. Os pesquisadores empregarm a técnica da análise temática de conteúdo para explorar o material coletado.

\section{Palavras-chave:}

Assistência farmacêutica, Saúde da Família, Cuidado em Saúde.

\section{Introdução}

A presença do profissional farmacêutico nas unidades de saúde da família facilita, entre outros, o uso racional dos medicamentos de forma integrada, contínua, segura e efetiva para o indivíduo, a família e a comunidade. Em outras palavras, o cuidado farmacêutico ao paciente visa promover a utilização adequada dos medicamentos e a otimização dos resultados de saúde. No entanto, o medicamento deixou de ser o único foco deste profissional, que também passou a cuidar do paciente, através de uma clínica. Interessa aos pesquisadores conhecerem como tem se dado a prática clínica dos farmacêuticos inseridos em unidades de saúde da família de Campinas.

OBJETIVO GERAL: conhecer a prática clínica dos farmacêuticos na Estratégia de Saúde da Família, no município de Campinas-SP.

\section{Resultados e Discussão}

Metodologia: de forma apriorística, os temas foram selecionados para a entrevista, a qual foi estudada e codificada pelo pesquisador para o processo de categorização.

Resultados: O cuidado farmacêutico apresenta maior relevância no contexto pós consulta médica para, principalmente, pacientes portadores de doenças crônicas ou que fazem uso da polifarmácia. É essencial que haja uma conversa entre o profissional e o paciente, para que sejam obtidas informações não só relacionadas ao medicamento, mas também questões mais amplas como a vida social, problemas pessoais e emocionais, que são pouco ou não abordadas nas rápidas consultas médicas, mas que também possam interferir, seja na qualidade de vida, seja no plano terapêutico.



Figura 1. Acesso ao cuidado farmacêutico.

O acesso é realizado por uma das formas da Figura 1, em que o paciente agenda uma consulta. Nesta, é realizado o registro em prontuário, embora estes profissionais não tenham um preparo para isso e para a realização da clínica, na graduação. Geralmente, os pacientes têm uma consulta de retorno, de forma a não ficarem desamparados.

- Fatores que facilitam a prática clínica farmacêutica são: a Estratégia de Saúde da Família e o apoio dado por profissionais que acreditam.

- Fatores que dificultam: sobrecarga pela dispensação de medicamentos; equipe mecanizada; profissionais que não aceitam interferência no trabalho; despreparo gerado na graduação.

Percepção: Os usuários do serviço sentem-se mais amparados pelo esclarecimento e apoio prestado pelo farmacêutico em diversas questões. Porém, os profissionais da unidade apresentam-se divididos, em os que apoiam e acreditam, outros neutros, e alguns que não validam este trabalho. E enfim, para o farmacêutico, esta modalidade de atendimento tem grande representação na satisfação profissional e pessoal.

\section{Conclusões}

É importante que haja o cuidado farmacêutico ao paciente, visto os benefícios proporcionados. No entanto, deve-se levar em conta um aprimoramento no processo de formação do profissional farmacêutico, a respeito da execução da clínica, do registro em prontuário e, principalmente, da questão ético-humanística, já que lidar com pessoas está tornando mais cotidiano.

\section{Agradecimentos}

Agradecimentos: SAE/PIBIC, FCM(departamento de Saúde Coletiva) e UNICAMP (Pró-Reitoria de Pesquisa).

- Hepler, CD. Clinical pharmacy, pharmaceutical care, and the quality of drug herapy. Pharmacotherapy, [S.1.], v.24, n.11, p.1491-1498, 2004.

- Congresso Conasems. Projeto Piloto de Cuidado Farmacêutica na Atenção Básica em Curitiba - Apresentação Congresso Conasems 2014.

- Hindmarsh, KW. Optimal drug therapy: the role of the pharmacist in bridging the gap between knowledge and action. The Canadian Journal of Clinical Pharmacology, [S.1.], v.8, n.2, p53A-54A, 2001 .Suppl. A. 